\title{
Práticas Laborais nas Salas de Aula de Matemática da EJA: perspectivas e tensões nas concepções de aprendizagem*
}

\author{
Labor Practices in Mathematics Classrooms of Adult Basic Education: \\ Stressing Learning Conceptions
}

\author{
Sonia Maria Schneider ${ }^{* *}$ \\ Maria da Conceição Ferreira Reis Fonseca ${ }^{* * *}$
}

\begin{abstract}
Resumo
Neste artigo, contemplamos intrincados jogos de intencionalidades e tensionamentos que se forjam nas - e que forjam as - práticas de numeramento na Educação de Pessoas Jovens e Adultas (EJA); em particular, focalizamos jogos que mobilizam práticas laborais de estudantes adultos da Educação Básica, posicionados ora como trabalhadores que estudam, ora como estudantes que trabalham. O material empírico foi produzido no acompanhamento, durante três semestres letivos, das aulas de matemática de duas turmas do segundo segmento do Ensino Fundamental na modalidade EJA numa escola pública. A análise destaca discursos de matrizes e motivações ideológicas e pedagógicas diversas e, por vezes, conflitantes. A identificação das formações discursivas que ecoam nas aulas de matemática da EJA e a explicitação dos marcos referenciais em que se apoiam e das tramas regulatórias em que se enredam são aqui empreendidas visando à compreensão daquelas práticas de numeramento como instâncias pedagógicas, de inclusão e de emancipação.
\end{abstract}

Palavras-chave: Práticas de Numeramento. Educação de Pessoas Jovens e Adultas. Educação e Trabalho. Práticas Discursivas. Etnomatemática.

\begin{abstract}
This paper aims at discussing intricate games of intentionalities and tensions, which are forged on numeracy practices (but also forge them) in Adult Education. We focus on the games that constitute efforts of using adult students' labor practices. These games position those adults sometimes as workers that go to school, sometimes as students that work. Our analysis is carried on an empirical produced by accompanying two Adult Education groups in their mathematic classes during three semesters. Those groups were attending the middle school for adults in a public school. This analysis highlights discourses from several ideological and pedagogical frames and motivations, sometimes in conflict. By identifying discursive formations in the adult mathematic classrooms and by putting in evidence their benchmarks and regulatory plots, this study aims at contributing for understanding those numeracy practices as pedagogical instances for inclusion and emancipation.
\end{abstract}

Keywords: Numeracy Practices. Youth and Adult Education. Education and Work. Discursive Practices. Ethnomathematics.

\footnotetext{
* A pesquisa que subsidiou a elaboração deste artigo teve apoio do CNPq.

Doutora em Educação pela Universidade Federal de Minas Gerais (UFMG). Professora Adjunta da Universidade do Estado do Rio de Janeiro (UERJ), Rio de Janeiro, RJ, Brasil. Endereço para correspondência: Rua Infante de Sagres 41, apto 202, Rio Comprido, CEP: 20261-160, Rio de Janeiro, RJ, Brasil. E-mail: somaria15@gmail.com.

*** Doutora em Educação pela Universidade Estadual de Campinas (UNICAMP). Professora Titular da Universidade Federal de Minas Gerais (UFMG), Belo Horizonte, MG, Brasil. Endereço para correspondência: Rua Conceição do Mato Dentro, 250, apto 1203A, Bairro Ouro Preto, CEP: 31310-240, Belo Horizonte, MG, Brasil.E-mail:mcfrfon@gmail.com.
} 
São dezoito horas e trinta minutos e ainda há poucos alunos e alunas na sala. Joelton (33) já estava sentado em sua carteira quando o professor Gilberto (50), acompanhado da pesquisadora (49), entra na sala. Esse é o primeiro dia de observação na turma 151. Enquanto esperam que mais alunos cheguem, pesquisadora e professor conversam sobre a pesquisa e o tema da Etnomatemática é trazido pelo professor ao referir-se à formação de professores de matemática da EJA, promovida pela Prefeitura na intenção de que o projeto das escolas se organize naquela perspectiva. De repente, o professor Gilberto se dirige ao quadro-negro e inicia a aula direcionando o olhar para o aluno Joelton, que está sentado na primeira carteira da fileira, o que o deixa muito próximo ao quadro-negro:

Professor Gilberto: Você é pedreiro, não?

Joelton: Sou.

O professor desenha no quadro um retângulo e indica as medidas de seu comprimento e sua largura.

$5 m$

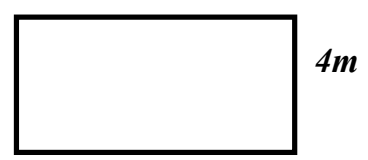

Enquanto desenha, pergunta:

Professor Gilberto: Para colocar um piso, sem rodapé, quantas caixas de dois metros você vai precisar?

Roberto (38): Vinte metros!

Professor Gilberto [olhando para Joelton]: Imagine que ela [olhando para a pesquisadora] chamou você para colocar um piso em sua casa...

Enquanto o professor Gilberto está atento ao Joelton, chegam outros alunos e alunas: Joane (23), Luciani (15) e Albanice (46) começam a conversar animadamente. Albanice, que, assim como Joelton, se senta na primeira carteira de sua fileira, e está mais perto do professor e de Joelton, ao perceber que o professor Gilberto colocara um problema no quadro, interrompe a conversa com Joane e Luciani e tenta participar arriscando uma resposta:

Albanice: Quatro? Cinco?

Como não obtém retorno do professor, que dirige a palavra e o olhar exclusivamente para o aluno Joelton, Albanice desiste da participação. Joelton, porém, não consegue responder e parece angustiado. O professor Gilberto muda de estratégia: dirige-se ao quadro, aponta para a figura do retângulo e as medidas e faz uma pergunta em voz alta, dirigindo o olhar para "a turma”, mas focalizando, novamente, ao final da pergunta, o aluno Joelton.

Professor Gilberto: De quantas caixas de dois metros você precisa para fazer isso?

Joelton [falando baixinho e olhando somente para o professor Gilberto]: Vinte?

Professor Gilberto [olhando para a turma]: Quantas vezes o dois cabe no vinte?

Albanice: Uma? Duas?

Roberto: Vinte?

Joelton: Vinte?

Roberto: Dez! São dez!

Professor Gilberto: Cada caixa tem dois metros, então, se vou cobrir vinte metros, de quantas caixas vou precisar?

E a seguir escreve no quadro:

\section{$2+2+2+2+2+2+2+2+2+2$}

Professor Gilberto [contando, ordenadamente, cada número dois que escreveu no quadro]: um, dois, três, quatro, cinco, seis, sete, oito, nove, dez.

Joelton [sem sair de seu lugar, chama o professor e fala baixinho]: Eu não preciso fazer conta. Eu só preciso saber a área que vou cobrir. $O$ vendedor da loja de material é que faz... Tem caixa de um e meio, tem caixa de dois...

Professor Gilberto [volta ao quadro e fala alto]: Mas, não é bom deixar sobrar alguma coisa? Não tem sempre quebra de alguns pisos?

Joelton [fala alto]: Sim. Uma sobra de dois dá.

Professor Gilberto [escrevendo no quadro]: E se eu tiver onze por dois? [enquanto fala o professor apaga as medidas dos lados do retângulo que foi desenhado no quadro e as substitui por esses novos valores]. Qual deverá ser a minha sobra? 
Joelton: A mesma! Dois metros!

Professor Gilberto: Qual é a área do retângulo?

Joelton: Vinte e dois metros.

Professor Gilberto: Então? Qual deve ser a minha sobra?

Joelton: A mesma! Dois metros bastam!

Joelton e o professor Gilberto continuam discutindo a questão da sobra. Como o horário máximo para a chegada de alunos é 19:30 h, as pessoas vão chegando, enquanto a aula está acontecendo. Chegam João (16) e Paula (17) e, quase ao mesmo tempo, Alzira (49). Joelton e o professor Gilberto não chegam a um consenso quanto à sobra, uma vez que para Joelton bastam dois metros e o professor Gilberto considera e reafirma que deve haver uma proporcionalidade entre a área e a sobra e que, portanto, quanto maior a área, maior deverá ser a sobra...

(Noite de $1^{\circ}$ de outubro, aula de Matemática, apontamentos do caderno de campo da pesquisadora)

A interação que reproduzimos acima, bem como os trechos de entrevistas que apresentaremos ao longo deste texto, foi selecionada no material empírico de uma investigação que focaliza interações que se processam nas aulas de Matemática de uma turma de pessoas jovens e adultas que cursam o Ensino Fundamental numa escola pública de um grande centro urbano brasileiro. Tais interações são analisadas como práticas discursivas que se forjam nas tensões estabelecidas por diversos marcadores sociais e que, por sua vez, alimentam e interpelam tais marcadores. Por isso, a exemplo do modo como se analisam tais práticas em outros trabalhos (SIMÕES, 2010; SCHNEIDER, 2010; SOUZA E FONSECA, 2010; FARIA, GOMES \& FONSECA, 2008; SOUZA, 2008; LIMA, 2007; MENDES, 2007; COBEN, 2006; BARWELL, 2004; TOLEDO, 2004,2003; BAKER, STREET \& TOMLIN, 2003, O’DONOGHUE, 2002; TOMLIN, BAKER \& STREET, 2002; EVANS, 2000; GAL, 1998), essas práticas são consideradas aqui práticas de numeramento - porque configuradas nas relações entre pessoas e entre grupos e na sua relação com conhecimentos, procedimentos ou critérios que associamos ao que aprendemos a chamar de Matemática, relações que são marcadas "pelas concepções de e sobre Matemática" e que "incluem valores que se atribuem à(s) matemática(s) em um dado contexto social, seja(m) essa(s) matemática(s) escolarizada(s) ou não escolarizada(s)" (FONSECA, 2010, p.329). Nesse sentido, ao tomá-las como práticas de numeramento, reconhecemos que essas interações implicam ações de poder, de legitimação ou de recusa de determinados modos de fazer matemática, "conferindo maior valor social a quem domina e mobiliza esse ou aquele modo, e não outros, de pensar, falar, produzir e utilizar Matemática" (idem). Há que se destacar, portanto, que, na abordagem das práticas de numeramento como práticas discursivas, como aqui pretendemos, procuramos contemplar a dimensão histórico-cultural (na qual se forjam as relações de poder e resistência) manifesta, “de modo especial, na adoção de recursos das linguagens (escritas e ou orais) que moldam as práticas de numeramento diferentemente para pessoas e/ou grupos" (idem). 
O material empírico da referida investigação foi produzido a partir do acompanhamento das aulas de Matemática de duas turmas do segundo segmento do Ensino Fundamental na modalidade Educação de Jovens e Adultos $(E J A)^{1}$ de uma escola pública municipal, durante três semestres letivos. As observações foram registradas por meio de audiogravação e apontamentos no caderno de campo. Além disso, foram feitas entrevistas individuais e coletivas com docentes e discentes dessas turmas, também audiogravadas. Esses registros subsidiaram a produção de narrativas que compuseram o corpo das análises naquela investigação e na qual os nomes originais dos sujeitos foram substituídos por pseudônimos, conforme o acordo com eles acertado de preservar sua identidade. Por se tratar de um estudo que problematizava a diversidade etária do público atendido por iniciativas de EJA, nas transcrições das interações e no texto das narrativas, as idades desses sujeitos vinham assinaladas entre parênteses após seu nome. Ainda que este texto não vá contemplar especificamente as tensões que envolvem a convivência em sala de aula das várias gerações que compõem o alunado da EJA, mantivemos aqui as referências às idades de estudantes, docentes e pesquisadoras, informação que consideramos relevante na contextualização das perspectivas e das concepções de aprendizagem que ecoam nas e forjam as práticas discursivas das aulas de Matemática voltadas para esse público.

Com efeito, com o material que ora selecionamos queremos discutir tais perspectivas e concepções, focalizando um aspecto recorrente nas interações que flagramos e que caracteriza um jogo de intencionalidades e tensionamentos nas práticas discursivas que envolvem a relação dos sujeitos com os conhecimentos escolares, em especial com os conhecimentos matemáticos que circulam - autorizada ou clandestinamente - nos contextos de aprendizagem que a escola propicia. Tal aspecto configura-se no convívio, nem sempre solidário, nem sempre conflituoso, das práticas (e dos discursos sobre as práticas) laborais e escolares, no repertório de referências para os processos de significação que se pretende estabelecer nas salas de aula da EJA, em especial, nas aulas de Matemática. Abordamos esse aspecto, aqui, identificando um duplo movimento, já evocado na enunciação com a qual o professor inicia a interação com seu aluno (Você é pedreiro, não?): de um lado, a suposição de que alunos e alunas da EJA têm conhecimentos matemáticos oriundos de sua vida não escolar, princípio que permeia o discurso da Educação Popular e, como herança, o da EJA, tanto quanto o das propostas que se fundamentam em abordagens etnomatemáticas (KNIJNIK et

\footnotetext{
${ }^{1}$ Como modalidade de oferta da Educação Básica, a EJA se caracteriza pelo atendimento de pessoas acima de 15 anos e/ou acima da faixa etária prevista para o ciclo que se está ofertando nessa modalidade; a oferta na modalidade EJA goza (e, em geral, usufrui) de algumas prerrogativas em relação à oferta regular, especialmente a da flexibilização do cômputo da carga horária e dos dias letivos.
} 
al., 2012); de outro lado, o questionamento que envolve o status conferido a esses conhecimentos matemáticos da vida de alunos e alunas da EJA em sua relação com os conhecimentos matemáticos escolares e sua repercussão no modo como tais conhecimentos se incorporam aos projetos pedagógicos que os mobilizam.

\title{
1 “Você é pedreiro, não?”: convocando a experiência do aluno-trabalhador
}

O enunciado "Você é pedreiro, não?" é a introdução escolhida pelo professor para a formulação de uma situação problema que parte da vida do aluno. Nesse sentido, o professor parece confirmar sua disposição de assumir a relevância dos conhecimentos da vida de alunos e alunas da EJA como um ponto de partida para as práticas escolares de ensino de Matemática, e ainda, de reafirmar a existência de conhecimentos matemáticos na vida dessas e desses estudantes adultos.

No enunciado “Você é pedreiro, não?”, portanto, é a experiência do aluno adulto trabalhador que é convocada para subsidiar a resolução da situação-problema que, dessa forma, partiria dessa experiência. Não é difícil identificar aí ecos do legado da Educação Popular que, por sua vez, inspira os princípios da Educação de Pessoas Jovens e Adultas e permeia também o discurso da Etnomatemática - discurso esse do qual o professor tivera a oportunidade de apropriar-se em atividades de formação docente das quais participava na ocasião.

Com efeito, a repercussão desse legado para as reflexões e propostas da Educação Matemática, especialmente aquela que se volta aos públicos da EJA, era já explicitada por Paulo Freire, na célebre entrevista concedida a Ubiratan D’Ambrósioº na década de 1990, ocasião em que Freire reafirma o esforço de partir do que o educando sabe como um dos princípios fundamentais para uma Educação Libertadora ou Emancipatória:

\begin{abstract}
Uma das coisas que a escola deveria fazer, e eu venho insistindo nisso há trinta anos ou mais, e fui muito mal entendido, e, ainda hoje continuo a ser, mas no começo fui muito menos entendido quando eu insistia que o ponto de partida da prática educativa deve ser, não a compreensão do mundo que tem o educador e o seu sistema de conhecimento, mas a compreensão do mundo que tem, ou que esteja tendo, o educando. A gente parte do que o educando sabe para que o educando possa saber melhor, saber mais e saber o que ainda não sabe (FREIRE, 1995, entrevista).
\end{abstract}

Arroyo (2006) reitera a importância da incorporação da herança acumulada da EJA para a formação de educadores. A incorporação dessa herança acumulada, entretanto,

\footnotetext{
${ }^{2}$ Disponível em: <http://acervo.paulofreire.org/xmlui/handle/7891/1880>_Acesso em: 07 set. 2013.
} 
implica considerar, na centralidade que deve ser conferida às pessoas jovens e adultas estudantes da EJA, sua condição de trabalhador em sua dimensão pedagógica e formadora. É nessa perspectiva que a EJA - "que sempre fez parte da dinâmica da sociedade, da dinâmica mais emancipadora" - se vincularia "muito mais aos processos de emancipação do que aos de regulação" (p.19).

A ativação dessa dinâmica mais emancipadora, suporia, portanto, compreender a Educação de Jovens e Adultos Trabalhadores

\begin{abstract}
como o conjunto de processos educativos destinados àqueles que vivenciam diversas interdições que as profundas assimetrias de poder inerentes à sociedade capitalista impõem à classe trabalhadora, no que se refere ao acesso pleno ao conhecimento (RUMMERT, 2006, p.124).
\end{abstract}

Rummert (2006), todavia, nos alerta para as duas concepções de trabalho que estão postas na atualidade, cuja adoção definirá, entre outras, as repercussões pedagógicas desse esforço de contemplar o mundo do trabalho no contexto das práticas de ensinagem e aprendizagem na escola: "aquela restrita aos limites da alienação e aquela que o toma como atualidade vital, como produção de existência”. Referindo-se ao clássico freiriano Educação como Prática de Liberdade (FREIRE, 1979), a autora afirma que Paulo Freire adota uma perspectiva ampliada do conceito de trabalho, e que seria nessa perspectiva que se deveria considerar a recomendação de trazer o mundo do trabalho para a sala de aula:

Podemos tomar, como exemplo, os comentários que apresentou [...], sobre as
pranchas representativas de situações existenciais com que iniciava seus trabalhos de
alfabetização de adultos. Nos comentários relativos à Primeira Situação: O homem
no mundo e com o mundo. Natureza e Cultura (p.124), apresenta o homem como
"um ser criador e recriador que, através do trabalho, vai alterando a realidade"
(Idem). Mais adiante, referindo-se à construção de um poço, Freire afirma: "O
homem fez o poço porque teve a necessidade de água. E o fez na medida em que,
relacionando-se com o mundo fez dele objeto de seu conhecimento. Submetendo-o
pelo trabalho, a um processo de transformação" (Ibid). Evidencia-se, assim, tanto a
concepção de trabalho desvinculada da alienação quanto o fato de que o trabalho
humano cria-se e recria-se na relação com o conhecimento (RUMMERT, 2006,
p.126).

As perspectivas pelas quais se considera(m), na sala de aula, o(s) mundo(s) do trabalho, porém, veiculam e alimentam-se de muitos discursos, por vezes conflitantes, o que faz de sua mobilização nos processos de significação de conceitos e procedimentos matemáticos um jogo delicado de intenções e efeitos de sentido.

Retomemos o enredo do diálogo que flagramos. A interação entre Joelton e o professor evoca uma cena anterior que deve ser reencenada. O professor reconhece que o aluno adulto tem um conhecimento matemático advindo de sua experiência de trabalho ("Você 
é pedreiro, não?”) e convoca essa experiência para nela calcar a abordagem de um conhecimento matemático escolar que ele já havia, de antemão, decidido apresentar aos alunos.

No evento acima narrado, a estratégia didática adotada pelo professor Gilberto é, pois, endereçada, de modo especial, àquele adulto, não só porque se reconhece o pertencimento desse aluno à categoria de trabalhador, mas também porque se avalia que ele precisa desse tipo de apoio pedagógico, como se pode depreender também no que disse o professor na entrevista concedida alguns meses antes àquela pesquisadora:

Professor Gilberto: (...) Mas o instrumento facilitador para a aprendizagem da matemática é tentar realizar um trabalho onde a gente leve em consideração as experiências de vida desses alunos. Eu não digo que isso não deve ser feito com relação aos mais jovens, mas abstrair para o adulto é muito mais difícil do que para o adolescente. (Noite de $1^{\circ}$ de julho, entrevista com o professor de Matemática)

Nesse trecho de uma das entrevistas realizadas com o professor Gilberto, a consideração das experiências de vida desses alunos é por ele evocada na abordagem das diferenças entre adolescentes e adultos quanto à aprendizagem matemática escolar, atribuindo à convocação dos conhecimentos advindos da experiência dos alunos adultos menos o papel de atualidade vital do que o de instrumento facilitador para a aprendizagem em matemática.

Essas duas perspectivas podem parecer solidárias, mas é preciso reconhecer entre elas uma tensão. Assumir que adultos na EJA aprendem Matemática baseando-se nas suas experiências de vida é uma posição que se pode referenciar naquele legado da educação popular e das concepções freireanas sobre a educação das pessoas adultas. Contudo, quando essa posição se justifica pela falta de uma competência necessária para a aprendizagem de Matemática - a abstração -, parece ecoar a noção de conhecimento evolutivo, segundo a qual o recurso à experiência concreta se refere ao infantil, ao inicial. Desse modo, denuncia a compreensão de que seria necessário reiniciar no adulto pouco escolarizado o seu processo de desenvolvimento intelectual, o que se faria "pela sua experiência", "desde o concreto".

As referências a tais dificuldades dos adultos da EJA para a aprendizagem matemática ecoam, pois, discursos que incorporam o que Dominique Colinvaux (2001) apresenta como traços recorrentes da noção de aprendizagem no ideário educacional:

[...] a idéia geral é que a noção de aprendizagem que, nos dias de hoje, norteia e sustenta grande parte de ações educativas (nacionais e internacionais) se inscreve numa perspectiva específica, um telos da educação ocidental, que atribui um papel central à racionalidade abstrata. Esta perspectiva específica é apoiada em estudos psicológicos (da psicologia cognitiva e da psicologia do desenvolvimento) que tomam como modelo de pensamento, ou ainda, como expressão máxima do pensamento, o pensamento científico. Qualquer que seja a base - psicológica ou 
epistemológica - a partir da qual aborda o estudo do pensamento, a perspectiva da racionalidade abstrata coloca em cena um pensamento puro, um pensamento que se libertou das amarras do corpo, do afeto, das influências sociais (p.1).

A ideia de que a aprendizagem deve ir do concreto ao abstrato é apontada por Colinvaux (2001) como o primeiro traço recorrente no ideário educacional sobre aprendizagem. A autora a associa à noção de estágios de desenvolvimento psicológico cognitivo, sobretudo "à caracterização do pensamento formal (hipotético-dedutivo ou abstrato) segundo a perspectiva piagetiana" (p.2). Ao buscar as justificativas para que esse traço seja tão forte nos meios educacionais, Colinvaux (2001) pondera que ele se associa tanto ao modo como se compreendem as competências intelectuais de pessoas adultas não escolarizadas (como a de crianças), quanto ao modo como se compreende o próprio conhecimento e o conhecer:

Este princípio é em parte tributário da noção de que as crianças - assim como os adultos não-escolarizados - são seres de competências intelectuais limitadas, lacunares: daí a necessidade de simplificar os conteúdos! Mas este princípio também está associado à perspectiva epistemológica para a qual o conhecimento se desenvolve de modo linear e acumulativo (p.3).

De certa maneira, essa compreensão das competências intelectuais de adultos pouco escolarizados e essa perspectiva epistemológica encontram acolhida nas concepções, hegemônicas nas sociedades ocidentais, que identificam raciocínio e inteligência com a capacidade de compreensão de estruturas. Essas concepções desconsideram o caráter marcadamente cultural dos processos cognitivos que costumamos resumir no termo raciocínio (e também o caráter marcadamente cultural das próprias concepções de raciocínio); no máximo, se preocupam com o quanto as práticas culturais diversificadas do sujeito podem comprometer sua capacidade de exercer aquele raciocínio lógico.

Tais discursos evocam, assim, modelos de racionalidade cartesiana que fundamentam a Matemática acadêmica, a Matemática escolar e muitas outras práticas de numeramento cotidianas que almejam uma legitimação social. Dessa maneira, não só os conteúdos disciplinares, mas principalmente didáticas e metodologias de ensino de Matemática são permeadas por essa racionalidade, assim como o são também as concepções sobre aprendizagem matemática.

Entretanto, essa aposta na mobilização do conhecimento do aluno numa perspectiva mais didática (como facilitador da aprendizagem) não é assumida por educadores da EJA sem alguma reserva: o estudo de Schneider (2005) sobre os dilemas práticos que se estabelecem para educadoras e educadores matemáticos de EJA aponta o tensionamento 
provocado pelos discursos sobre a importância dos saberes, ou das vivências, ou ainda, das experiências dos alunos como ponto de partida para as práticas docentes na EJA que, se, por um lado, apoiam-se na hipótese de uma especificidade do alunado da EJA e de seus modos de aprender, por outro lado, poderão forjar também uma hipótese de especificidade da Matemática da EJA, que a diferenciaria da Matemática da escola regular - essa, inacessível às alunas e aos alunos da EJA - pelos graus de complexidade ou níveis de abstração. Estabelecese assim "um dilema constante que se constitui entre os discursos e as práticas na EJA" (p.71). Segundo aquele estudo, "há, nesse dilema, a revelação de que (...) a mesma experiência que parece ser considerada para as ações que se voltam para esses alunos é a que os desqualifica para as aprendizagens escolares” (SCHNEIDER, 2005, p.71).

\section{2 “Eu não preciso fazer conta”: dificuldades na escuta do trabalhador-aluno}

$\mathrm{Na}$ interação que é narrada no evento que abre este artigo, a experiência de trabalhador de Joelton acaba não servindo à produção do conhecimento matemático previsto pelo professor. De fato, o enunciado da pergunta "De quantas caixas de dois metros você vai precisar?" não expressa uma curiosidade genuína do professor sobre o modo como o aluno resolve um problema prático. Pelo contrário, essa formulação prevê uma certa resposta que, seguindo o script, se relacionaria com a solução do problema pela Matemática da escola.

Joelton traz para o evento uma contribuição não esperada pelo professor ao afirmar "Eu não preciso fazer conta" porque basta "saber a área que vou cobrir" já que "O vendedor da loja de material é que faz (a conta)”, e, além disso, a quantidade de piso nas caixas varia, pois, há caixas "de um e meio" e "de dois [metros quadrados de piso]".

$\mathrm{O}$ trabalhador-aluno, ao atender à convocação de mobilização do conhecimento de sua prática profissional, mantém-se fiel às práticas de numeramento forjadas no ambiente de trabalho, negando-se ao jogo da aprendizagem escolar, no qual o aluno deve despojar-se dos modelos nos quais suas práticas de numeramento são forjadas, esvaziando-se, para se deixar ocupar pelos modelos que fundamentam uma certa prática de numeramento escolar.

Joelton nega-se a entrar nesse jogo em que o professor propõe uma situação hipotética ("se vou cobrir vinte metros...") como um passo para a generalização (já que "abstrair para o adulto é muito dificil"). Como que tentando restabelecer sua experiência profissional como parâmetro da discussão, o aluno chama o professor e esclarece que, na situação real, ele não precisa fazer conta: "Eu só preciso saber a área que eu vou cobrir. $O$ 
vendedor da loja de material é que faz" (a conta de quantas caixas são necessárias), até porque "Tem caixa de um e meio, tem caixa de dois".

A reação do professor denuncia o quanto é difícil para nós, educadores, assumirmos a incompletude e a não universalidade do conhecimento escolar, e, particularmente, dos critérios da Matemática que se ensina na escola.

O professor Gilberto, que se dispôs a "partir do conhecimento do aluno (trabalhador)", não se permite, contudo, investigar a solução que é dada pelo trabalhador-aluno ao problema real, pois tal solução não parece servir à estratégia argumentativa que o docente traçaria para legitimar o conhecimento escolar que lhe cabia apresentar a seus alunos.

Desse modo, embora os discursos sobre a relevância do conhecimento do aluno da EJA reafirmem a relevância da Matemática da vida desse adulto para a Matemática da escola, o compromisso com o fluxo das práticas de numeramento escolares instaura uma contradição: o aluno atende à convocação do professor de recorrer à sua experiência, mas, com isso, essa experiência de trabalhador subverte a intenção da convocação.

Com efeito, a intenção de forjar o que seria um novo status da Matemática da vida na abordagem escolar sucumbe à força da negação dos modos de conhecer do mundo do trabalho do aluno da EJA e desse aluno nesse mundo. Nesse sentido, precisamos estar atentos ao alerta de Arroyo (2006) em relação às restrições que impomos à manifestação do conhecimento da vida no contexto escolar e à sua acolhida como oportunidade educativa: "Com esse olhar não captaremos as marcas formadoras ou deformadoras que levam do trabalho. Perderemos a oportunidade de reconhecer o trabalho como matriz educativa" (ARROYO, 2006, p. 126).

Nos discursos sobre a importância das vivências dos alunos adultos da EJA, emerge um sujeito social e cultural. No entanto, no acontecimento da sala de aula, esse sujeito - o educando - deve dar lugar ao estudante, que deve tornar-se aluno num processo, no qual o sujeito suposto nas orientações curriculares, no material didático, ou ainda nos discursos sobre a matemática na EJA, deve corresponder às suposições sobre (e comportar-se como) aprendiz:

Ser aluno é ser estudante (aquele que estuda) ou aprendiz (aquele que aprende); são categorias descritivas de uma condição que supõe trazer unidos determinados comportamentos, regras, valores e propósitos que devem ser adquiridos por quem pertence a essa categoria (SACRISTÁN, 2005, p. 125).

Sacristán (2005) ressalta que essas categorias são criadas, propostas e impostas no âmbito da instituição escolar e "proporcionam uma nova identidade àqueles que têm essa condição que é reconhecida socialmente". Para o autor, “a forma como são realizadas as 
funções que essa instituição tem e sua acomodação ao papel que se espera dos menores" [educandos] determinarão o valor que se atribuirá ao aluno como "estudante ou aprendiz" (p.125).

A tensão entre, de um lado, um suposto sujeito da EJA, evocado nos discursos sobre os saberes da vida, e, de outro lado, os discursos de e sobre a Matemática na EJA incorpora, ainda, um outro constituinte: esses sujeitos supostos são adultos e, desse modo, em seu processo de se tornarem estudantes e aprendizes, devem aderir a essa nova posição, a uma identidade forjada na escola de EJA, na qual o seu tempo de adulto, a sua idade, a sua experiência, fartamente evocados nos discursos sobre a Matemática na vida de educandos adultos de EJA, devem moldar-se aos propósitos educativos da escola.

Talvez por isso, não ocorra ao professor problematizar na sala de aula de Matemática, a experiência do aluno adulto, que lhe diz que não precisa fazer conta porque é um outro quem faz, naquilo que ela revela das condições e das relações de trabalho às quais o adulto trabalhador, aluno de EJA, está submetido. Essa discussão, fundamental para a compreensão que terá o próprio sujeito adulto sobre seu processo de produzir e de se apropriar do conhecimento matemático, parece não se colocar para o professor de Matemática da EJA como conteúdo a ser trabalhado partindo da experiência do aluno.

\title{
3 "Porque a vida está cobrando essa matemática deles": critérios de adesão a um projeto político-pedagógico
}

\begin{abstract}
Professor Gilberto: (...) O trabalho na educação de jovens e adultos, com o adulto, a gente tem que valorizar as experiências de vida. Agora, a gente entra em choque quando a gente começa a trabalhar com álgebra... Você relacionar alguma coisa de álgebra com a experiência de vida deles é inventar o que não tem como... Porque, por exemplo, a gente vai trabalhar expressões algébricas... Dá para associar a expressão algébrica a algum aspecto cultural do aluno? De certa forma sim, mas ele tem que perceber que ele vai trabalhar expressão algébrica porque ele futuramente vai trabalhar o cálculo de uma velocidade, ele vai ter que atribuir valores diferentes, numa situação diferente, daquela forma, entendeu? Então, existe este outro lado, também técnico, que a gente não pode afastar o aluno, porque, eu estava conversando com o Milton, quando a gente estava fazendo o curso de etnomatemática, que a gente não pode tirar esse direito dele, de aprender essa matemática, porque a vida está cobrando essa matemática deles. (Noite de $1^{\circ}$ de julho, entrevista com o professor de Matemática)
\end{abstract}

No trecho acima, selecionado entre as declarações do professor Gilberto em entrevista concedida às pesquisadoras, emerge um outro aspecto conflituoso na mobilização do conhecimento do aluno e de sua relação com o conhecimento escolar. O professor aponta a complexidade supostamente inerente à Matemática, e relacionada ao desenvolvimento do currículo escolar, como mais uma dificuldade para "valorizar as experiências de vida" do 
aluno da EJA, uma vez que, para a abordagem de determinados conteúdos escolares, a vida cotidiana dos adultos trabalhadores, estudantes de EJA, dificilmente ofereceria possibilidades de estabelecimento de relações.

Nesse depoimento, a experiência do aluno adulto da EJA parece prestar-se como referência apenas para a abordagem de conteúdos mais elementares, de menor exigência de abstração, de menor complexidade entre os que devem ser contemplados pela Matemática da escola. Com o avanço das séries, a tensão entre a potencialidade pedagógica da experiência do aluno e as demandas de aprendizagem do currículo escolar é intensificada: a complexidade dos conteúdos "entra em choque" com a possibilidade de "valorizar as experiências de vida do aluno adulto", pois "será que dá para associar a expressão algébrica a algum aspecto cultural do aluno?”.

Essa enunciação, ao chamar à cena o "aspecto cultural do aluno", sugere uma polarização: os aspectos culturais do aluno adulto (da EJA), num polo, e os aspectos culturais da escola, no outro. O professor fala em "aspectos culturais do aluno", mas não fala em cultura da escola que aparece, porém, no seu discurso, identificada pela metonímia da "expressão algébrica" com toda sua carga de exacerbação do aspecto sintático da Matemática que se ensina na escola.

Mobiliza-se, assim, uma certa concepção de aluno adulto pela identidade que lhe confere o "seu aspecto cultural", ao qual a escola deve ter acesso, para partir dele. Mas a escola não quer ser também considerada em seu aspecto cultural, pois isso fragilizaria a ilusão de universalidade que ela quer conferir ao conhecimento que veicula.

Knijnik (2006) aborda a complexidade do conceito de cultura e, mais especificamente, de cultura popular para a Etnomatemática, considerando-se que a essa abordagem não só cabe o estudo das "matemáticas dos grupos sociais subordinados, enfatizando sua coerência interna", mas também "inclui examinar a matemática popular restaurando sua necessidade prática, relacionando-a com as condições reais de sua gênese" (p.173). Em sua reflexão, a autora retoma as críticas à Etnomatemática, segundo as quais,

[...] se, por um lado, a Etnomatemática (re)conhece - e valoriza - as "outras" matemáticas, pondo em destaque as diferenças culturais, tão enfatizadas pelas posições pós-modernas, por outro lado, para falar destas diferentes matemáticas ela se utiliza da Matemática acadêmica, impregnada pela racionalidade, pela primazia da razão. Nada mais "moderno" do que o discurso da Matemática oficial e o papel que este vem desempenhando na (re)produção dos valores da modernidade! (p.174 grifos da autora).

Para Knijnik (2006), entretanto, tais críticas atribuiriam à Etnomatemática um 
propósito que ela "sequer tem a pretensão de ter": o de "ser uma 'resposta' da Educação Matemática aos 'problemas' da Modernidade” (p.174). A argumentação de Knijnik (2006) a respeito desse paradoxo da Etnomatemática, por sua vez, remete às fragilidades das teorias relativistas às quais, do seu ponto de vista, "os estudos etnomatemáticos (resguardando sua heterogeneidade), pelo menos em princípio, estão filiados” (p.174).

Nas cenas que flagramos naquela escola de EJA, contudo, discursos e disposições atribuídos à Etnomatemática foram convocados nas enunciações do professor, nas quais ecoam também os tensionamentos a que sua prática pedagógica se vê submetida. Nessa escola, embora os discursos sobre a importância de considerar as experiências dos alunos permeiem o encaminhamento da aula de Matemática, o aspecto cultural a ser considerado é $d o$ outro, que é o aluno de EJA. A relação entre culturas não é objeto de estudo - isso não se coloca como um objetivo da escola. O conhecimento do aluno adulto de EJA é perspectivado em relação à cultura da escola, o permite denotar a sua diferença em relação ao conhecimento escolar e revelar uma falta no aluno de EJA, afirmando a cultura escolar como uma meta e como um modelo para esse aluno em falta.

No discurso do professor, a noção de cultura, evocada na polarização conhecimento do aluno adulto de EJA versus currículo de Matemática da escola, remete a uma distinção entre culturas, de acordo com a qual a cultura do aluno adulto parece ser compreendida como um estágio anterior, primitivo, da cultura escolar. Assim, nos níveis mais elementares do currículo, a tensão entre ambas é suportável, porém, nos níveis mais avançados do currículo, não dá para associar a expressão algébrica a algum aspecto cultural do aluno.

Desse modo, se trazer a Matemática da vida para o contexto escolar de EJA configura o aluno adulto de EJA como aquele "possuidor de um aspecto cultural" que deve ser considerado, a perspectiva pela qual se considera o tal aspecto cultural, no entanto, posiciona o aluno como aquele que terá dificuldades em conciliar, ou ao menos relacionar, a sua cultura com os conteúdos mais sofisticados (mais escolares) da escola.

\section{Considerações finais}

$\mathrm{Na}$ reflexão que propusemos neste artigo, bem como em toda a análise desenvolvida ao longo da investigação que o subsidia, procuramos contemplar os intrincados jogos de intencionalidades e tensionamentos que se forjam nas - e que forjam as - práticas 
discursivas da sala de aula da Educação de Pessoas Jovens e Adultas. Aqui, em particular, focalizamos tensões e intenções que configuram os esforços de mobilização das práticas laborais de estudantes adultos da Educação Básica, posicionados ora como trabalhadores que estudam, ora como estudantes que trabalham.

Nessa mobilização ecoam discursos de uma matriz ideológica comprometida com um projeto emancipatório, legado da Educação Popular, referenciados nas teorizações de Paulo Freire, e no modo como tais teorizações, formuladas a partir das experiências vividas, promovidas, testemunhadas ou sonhadas por aquele educador, foram sendo apropriadas pelo discurso pedagógico, em especial, por aquele que se veicula nas instâncias de formação de educadoras e educadores de pessoas jovens e adultas.

Mas a mobilização, com motivações pedagógicas e propósitos didáticos, das práticas laborais de alunas e alunos da EJA, nos contextos de aprendizagem escolar, especialmente nos contextos de aprendizagem da Matemática escolar, ecoa também formulações a respeito dos processos cognitivos envolvidos nessa aprendizagem formulações que pretendem justificar avaliações e suspeitas sobre as (in)capacidades intelectuais de sujeitos jovens e adultos pouco escolarizados para lidar com abstrações ou com jogos simbólicos organizados a partir de regras exclusivamente sintáticas. Nessas formulações, percebem-se os mecanismos regulatórios gestados sob os paradigmas da modernidade, que conformam não apenas os modos de pensar e gerir a vida escolar, mas também os modos de relação com o(s) mundo(s) do trabalho, na escola e fora dela.

As práticas discursivas protagonizadas por discentes e docentes na sala de aula não estarão, por certo, imunes às ressonâncias desses ecos. Por isso, a compreensão e a potencialização dessas práticas como instâncias pedagógicas, de inclusão e de emancipação supõem uma disposição de se identificarem as formações discursivas que ali ecoam, de se explicitarem os marcos referenciais em que se apoiam, de se denunciarem as tramas regulatórias em que se enredam, mas também de se acolherem a diversidade, a ambivalência e a transitoriedade das posições assumidas pelos sujeitos.

\section{Referências Bibliográficas}

ARROYO, M. G. Formar Educadores e Educadoras de Jovens e Adultos. In: SOARES, L. (Org.). Formação de Educadores de Jovens e Adultos. Belo Horizonte: SECAD/MEC/UNESCO/ Autêntica, 2006. p.17-32.

BAKER, D.; STREET, B.; TOMLIN, A. Mathematics as Social: understanding relationships between home and school numeracy practices. For the learning of mathematics, Fredericton, v. 23, n. 3, p. 
11-15, nov. 2003.

BARWELL, R. What is numeracy? For the learning of mathematics, Fredericton, v. 24, n. 1, p. 2022, mar. 2004.

COBEN, D. What is specific about research in adult numeracy and mathematics education? Adults Learning Mathematics - An International Journal, Washington DC, v. 2, n.1, p. 18-32, nov., 2006.

COLINVAUX, D. Aprendizagem: um tema em aberto? Rio de Janeiro: Manuscrito, 2001.

EVANS, J. Adults' Mathematical Thinking and Emotions: a study of Numerate Practices. London: Routledge Falmer, 2000.

FARIA, J. B; GOMES, M. L.; FONSECA, M. C. F. R. A artificialidade da dicotomia entre saberes cotidianos e saberes escolares na mobilização e constituição de práticas de numeramento na sala de aula da educação de jovens e adultos. In: Terceiro Congresso Brasileiro de Etnomatemática, 3.,. 2008, Niterói. Anais... Niterói: Faculdade de Educação da Universidade Federal Fluminense, 2008. p.1-15.

FONSECA, M. C. F. Matemática cultura escrita e numeramento. In: Marildes MARINHO. G. T. C. (Org.). Cultura escrita e letramento. Belo Horizonte: Editora UFMG, 2010. p. 321-335.

FREIRE, P. Educação como prática da liberdade. Rio de Janeiro: Paz e Terra, 1979.

FREIRE, P. Paulo Freire e a Educação Matemática: entrevista concedida à Ubiratan D'Ambrósio. 1995. Disponível em: <http://acervo.paulofreire.org/xmlui/handle/7891/1880>. Acesso em: 10 de set. 2013.

GAL, I. Numeracy education and empowerment: research challenges. In: VAN GROENESTIJN M.; COBEN, D. (Org.). Proceedings of the fifth international conference of Adults Learning Mathematics (ALM-5). London: Goldsmiths University of London, 1998. p. 9-19.

KNIJNIK, G. Educação matemática, culturas e conhecimento na luta pela terra. Santa Cruz do Sul: EDUNISC, 2006.

KNIJNIK, G.; WANDERER, F.; GIONGO, I. M.; DUARTE, C. G. Etnomatemática em movimento. Belo Horizonte: Autêntica, 2012.

LIMA, P. C. Constituição de práticas de numeramento em eventos de tratamento da informação na educação de jovens e adultos. 2007. 103 f. Dissertação (Mestrado em Educação)- Programa de Pós-graduação em Educação: Conhecimento e Inclusão Social, Universidade Federal de Minas Gerais, Belo Horizonte, 2007.

MENDES, J. R. Matemática e práticas sociais: uma discussão na perspectiva do numeramento. In: MENDES; GRANDO, R. C. Múltiplos olhares: matemática e produção de conhecimento. São Paulo: Musa Editora, 2007. p.11-29.

O'DONOGHUE, J. Numeracy and Mathematics. Irish Math. Soc. Bulletin, Irlanda, n. 48, p. 47-55, Summer, 2002.

RUMMERT, S. M. Formação Continuada de educadores de jovens e adultos: desafios e perspectivas. In: SOARES, L. (Org.). Formação de Educadores de Jovens e Adultos. Belo Horizonte: SECAD/MEC/UNESCO/Autêntica, 2006. p.123-140.

SACRISTÁN, J. G. O Aluno como Invenção. Trad. Daisy Vaz de Moraes. Porto Alegre: Artmed, 2005. 
SCHNEIDER, S. M. A consideração de dilemas práticos para a formação de professores em educação matemática de jovens e adultos. 2005. 85 f. Dissertação. (Mestrado em Educação)Programa de Pós-graduação em Educação, Universidade Federal Fluminense, Niterói, 2005.

SCHNEIDER, Sônia M. Esse é o meu lugar...Esse não é o meu lugar: relações geracionais e práticas de numeramento na escola de EJA. 2010. 211 f. Tese (Doutorado em Educação) - Programa de Pósgraduação em Educação: Conhecimento e Inclusão Social, Universidade Federal de Minas Gerais, Belo Horizonte, 2010.

SIMÕES, F. M. Apropriação de práticas de letramento (e de numeramento) escolares por estudantes da EJA. 2010. 190 f. Dissertação (Mestrado em Educação)- Programa de Pós-graduação em Educação: Conhecimento e Inclusão Social, Universidade Federal de Minas Gerais, Belo Horizonte, 2010.

SOUZA, M. C. R. Gênero e matemática(s) - jogos de verdade nas práticas de numeramento de alunas e alunos na Educação de Pessoas Jovens e Adultas. 2008. 317 f. Tese (Doutorado em Educação)- Programa de Pós-graduação em Educação: Conhecimento e Inclusão Social, Universidade Federal de Minas Gerais, Belo Horizonte, 2008.

SOUZA, M. C. R. F; FONSECA, M. C. F R. Relações de gênero, Educação Matemática e discurso: enunciados sobre mulheres, homens e matemática. Belo Horizonte: Autêntica, 2010.

TOLEDO, M.. As estratégias metacognitivas de pensamento e o registro matemático de adultos pouco escolarizados. 2003. 228 f. Tese (Doutorado em Psicologia da Educação) - Programa de Pósgraduação em Psicologia da Educação, Universidade de São Paulo, São Paulo, 2003.

TOLEDO, M. E. R. O. Numeramento e escolarização: o papel da escola no enfrentamento de demandas matemáticas cotidianas. In: FONSECA, M. C. F. R. (Org.). Letramento no Brasil: habilidades matemáticas. São Paulo: Global: Ação Educativa, Assessoria, Pesquisa e Informação: Instituto Paulo Montenegro, 2004. p. 91-105.

TOMLIN, A.; BAKER, D.; STREET, B. Home and school numeracy practices: Where are the borders and overlaps? In: VALERO, Paola. SKOVSMOSE, O. Proceedings of the 3rd International MES Conference. Copenhagen: Centre for Research in Learning Mathematics, 2002. p. 1-10. Disponível em <http://www.mes3.learning.aau.dk/Papers/ Tomlin_et_al.pdf>. Acesso em 11 jun. 2009.

Submetido em Outubro de 2013. Aprovado em Abril de 2014. 